\title{
Epidemiological patterns of traumatic musculoskeletal injuries and non-traumatic disorders in Japan Self-Defense Forces
}

\author{
Masatoshi Amako ${ }^{1 *} \mathbb{D}$, Yoshiyuki Yato ${ }^{1}$, Yasuo Yoshihara', Hiroshi Arino ${ }^{1}$, Hiroshi Sasao 1,2, Osamu Nemoto², \\ Tomohito Imai ${ }^{3}$, Atsushi Sugihara ${ }^{4}$, Satoshi Tsukazaki ${ }^{5}$, Yutaka Sakurai ${ }^{6}$ and Koichi Nemoto ${ }^{1}$
}

\begin{abstract}
Background: The epidemiological patterns of musculoskeletal injuries or disorders in military personnel have not been well documented and a better understanding is required for proper preventative measures and treatment. Here, we investigated musculoskeletal injuries or disorders among members of the Japan Self-Defense Forces.

Methods: All orthopedic patients $(n=22,340)$ who consulted to Japan Self-Defense Forces Hospitals were investigated for their type of injury or disorder, the injured body part, the mechanism, and the cause of injuries.

Results: Thirty-nine percent of the cases were classified as traumatic injuries, and $61 \%$ were classified as non-traumatic disorders. Of the traumatic injury patients, the injured body part was the upper extremity in 32\%, the trunk in $23 \%$, and the lower extremities in $45 \%$ of the cases. The most common injured body location was the knee followed by the hand/finger and ankle. Exercise was the most common cause of injury, followed by traffic accident and military training.

Contusions were the most common traumatic injuries, followed by sprains and fractures. Of non-traumatic disorders, the lower extremities were reported as the injured part in $43 \%$ of the disorders. Lumbar spine disorders were the most common non-traumatic disorders, followed by tendon and joint disorders.

Conclusions: Over one-third of orthopedic cases among members of the Japan Self-Defense Forces are traumatic injuries, with the knee being the body part most commonly injured and exercise being the leading cause of injury.
\end{abstract}

Keywords: Musculoskeletal injury, Non-traumatic musculoskeletal disorder, Epidemiological surveillance, Fracture risk, Body mass index

\section{Background}

Current recommendations suggest that engaging in regular physical activity reduces cardiovascular events and many chronic diseases (Haskell et al., 2007). Increasing the amount of physical activity also increases the risk of musculoskeletal injuries or disorders. The Japan Health Labour and Welfare Ministry reported that fracture and joint disorder were major reasons for the need of long-term nursing care in Japan (Japan Health, Labor and Welfare Ministry, 2017). However, the prevalence musculoskeletal injuries or disorders is unclear. Recently,

\footnotetext{
*Correspondence: amako@ndmc.ac.jp

'Department of Orthopaedic Surgery, National Defense Medical College, 3-2 Namiki, Tokorozawa, Saitama 359-8513, Japan

Full list of author information is available at the end of the article
}

epidemiological studies of musculoskeletal disorders were conducted in Japan (Muraki et al., 2010; Yoshimura et al., 2009; Yoshimura et al., 2011; Tsunoda et al., 2013), with elderly subjects as the main population of their studies and degenerative disorders, such as osteoarthritis, spondylosis, and osteoporosis, examined. Musculoskeletal injuries or disorders are a common health problem for young populations, and a preventive system should be required using epidemiological data. Sports injury surveillance, as an epidemiological study, has been conducted in young athletes (Fukubayashi et al., 2010; Fukubayashi et al., 2012; Fukubayashi et al., 2013). However, the military population may also be ideal for obtaining epidemiological data of musculoskeletal problems. The United States Military has performed large injury surveillance studies, and 
the biggest health problem was traumatic injuries, especially lower extremity, training-related injury (Jones et al., 2010; Jones et al., 1993). Military medical corps in other foreign nations have also reported injury surveillance data (Frilander et al., 2012; Taanila et al., 2009). However, no previous studies of musculoskeletal disorders in a young military population in Japan. The purpose of the present study was to survey musculoskeletal injuries and disorders among military personnel in the Japan Self-Defense Forces, to analyze risk factors, and to compare to other athletic, military, and Japanese populations. Moreover, we also identified risk factors of fracture in the traumatic injury, and we hypotheses the risk factors of fracture were obesity and/or smoker. Ultimate aim of this study was to minimize these factors to prevent such musculoskeletal injuries or disorders in the Japanese Self Defense Forces members.

\section{Methods}

With approval of our institutional review board (IRB No. 895), a longitudinal cohort study of musculoskeletal injuries and disorders was investigated in 13 Japan SelfDefense Forces Hospitals between 2008 and 2012. All patients with musculoskeletal problems were referred to the orthopedic outpatient clinic in the hospitals. Review sheets were provided at the first visit, and patients were asked to complete the review sheets on a voluntary basis and provide written informed consent. The review sheet included 17 questions concerning a time and date, age, sex, height, weight, rank, branch, uniformed service, service years, right/left, cause and sites of disorders, mechanism of injury, past history, smoking, and alcohol habits. These questions included several options, and patients chose the options before visiting to surgeons. The options of "cause of injury" included exercise, military training, repairing work, traffic accident, activity of daily living, and others. Exercise included sports in a club team, personal fitness, and jogging. On the other hand military training included official training during wearing boots, helmet, and uniform. The options of "mechanism of injury" included sprain, bruising, falling, outstretched, squeezing, lifting objects, cuts, being stepped on and others. After a medical examination, orthopedic surgeons reported the diagnosis on the review sheets. The data was collected and analyzed at our institution.

The inclusion criteria for this study were patients with musculoskeletal problems who were associated with the Japan Self-Defense Forces, including cadets. The exclusion criteria were retired members, civilian members, service members' families, unconscious patients, patients without written informed consent, returning patients with the same diagnosis over a couple of months, patients with injuries to the head or face, and patients without musculoskeletal injuries or disorder.
We divided the patients with musculoskeletal problems into two groups: the traumatic injury group and the non-traumatic injury group. The traumatic injury group is defined as patients with bodily harm resulting from acute exposure to external forces, including fracture, joint dislocation, sprain, and contusion. The nontraumatic musculoskeletal disorder group is defined as patients with injury-related musculoskeletal conditions resulting from the cumulative effects of smaller amplitude forces that occur with over-training, repetitive movements, and forceful actions, including osteoarthritis, tendinitis, non-traumatic lower back pain, fatigue fracture, and entrapment neuropathy.

We focused on fracture in this traumatic injury group, and divided the patients into two additional groups: the fracture group and the non-fracture group. Risk factors in regards to gender, body mass index (BMI), age, type of uniformed service, rank, smoking, and alcohol habit were evaluated. BMI was divided into 4 groups based on the World Health Organization (WHO, BMI classification 1994)(The World Health Organization BMI classification, 1994): underweight (BMI < 18.5), normal weight $(18.5 \leq \mathrm{BMI}<25)$, overweight $(25 \leq \mathrm{BMI}<30)$, and obese $(30 \leq \mathrm{BMI})$. The associations of the 4 different weight classes and fractures were assessed by multiple logistic regression models to estimate odds ratios (OR) and 95\% confidence intervals $(\mathrm{CI})$. All models were adjusted for age, type of uniformed service, rank, smoking, and alcohol habit, and physical grade.

Statistical analyses were performed using Student's $\mathrm{t}$ test, repeated measure ANOVA test, and the chisquared test. A multivariable analysis was performed using logistic regression analysis, and the odds ratio $(\mathrm{OR})$ and confidence intervals $(\mathrm{CI})$ were obtained. We carried out the analyses using JMP 10 (SAS Institute Japan, Tokyo).

\section{Results}

The total number of patients with musculoskeletal problems was 22,340 during the study period, including 1458 females, 20,718 males, and 164 nonresponders. The mean age was $35.2 \pm 10.8$ years (range, 15-60 years). The mean weight was $69.2 \pm 10$. $7 \mathrm{~kg}$ (range, 32-138 kg), the mean height was 170.2 $\pm 6.4 \mathrm{~cm}$ (range, 147-199 cm), and the mean body mass index was $23.8 \pm 3.1$ (range, 11.7-44.1). Of the patients, 14,432 were in the Grand Force, 5787 in the Maritime Force, 1285 in the Air Force, and 836 were cadets. The population by rank included 4105 officers, 12,292 enlisted, 4611 soldiers, and 836 cadets (nonresponder 496). We obtained 26,837 musculoskeletal diagnoses during the study period, with 10,442 traumatic injuries (38.9\%), and 16,395 non-traumatic disorders $(61.0 \%)$ (Table 1$)$. 
Table 1 Comparison of baseline demographics of patients between traumatic musculoskeletal injury and non-traumatic disorder

\begin{tabular}{|c|c|c|c|c|c|}
\hline \multirow{2}{*}{ Total No. } & & \multicolumn{2}{|c|}{ Traumatic injuries } & \multicolumn{2}{|c|}{ Non-traumatic disorders } \\
\hline & & 10,442 & & 16,395 & \\
\hline Average age (y) & & 33.7 & $15-60$ y & 36.4 & $15-60 y$ \\
\hline \multirow[t]{6}{*}{ Age distribution } & $15-19 y$ & 573 & $5.5 \%$ & 1093 & $6.7 \%$ \\
\hline & $20-29 y$ & 3646 & $34.9 \%$ & 4154 & $25.3 \%$ \\
\hline & $30-39 y$ & 2864 & $27.4 \%$ & 3789 & $23.1 \%$ \\
\hline & $40-49$ y & 2452 & $23.5 \%$ & 4952 & $30.2 \%$ \\
\hline & $50-60$ y & 907 & $8.7 \%$ & 2394 & $14.6 \%$ \\
\hline & non-responder & & & 13 & $0.0 \%$ \\
\hline \multirow[t]{3}{*}{ Sex } & male & 9701 & $93.2 \%$ & 15,138 & $92.6 \%$ \\
\hline & female & 660 & $6.3 \%$ & 1140 & $7.0 \%$ \\
\hline & non-responder & 81 & $0.8 \%$ & 117 & $0.7 \%$ \\
\hline \multirow[t]{4}{*}{ Alcohol habit } & drink everyday & 2132 & $21.0 \%$ & 3363 & $20.5 \%$ \\
\hline & drink sometimes & 6290 & $60.2 \%$ & 9850 & $60.1 \%$ \\
\hline & non-drinker & 1472 & $14.5 \%$ & 2314 & $14.1 \%$ \\
\hline & non-responder & 548 & $5.2 \%$ & 868 & $5.3 \%$ \\
\hline \multirow[t]{3}{*}{ Smoking habit } & smoker & 3974 & $38.1 \%$ & 6289 & $38.4 \%$ \\
\hline & non-smoker & 6138 & $58.8 \%$ & 9564 & $58.3 \%$ \\
\hline & non-responder & 330 & $3.2 \%$ & 542 & $3.3 \%$ \\
\hline \multirow[t]{4}{*}{ Uniformed service } & Ground Force & 6752 & $64.7 \%$ & 11,066 & $67.5 \%$ \\
\hline & Maritime Force & 2593 & $24.8 \%$ & 3988 & $24.3 \%$ \\
\hline & Air Force & 528 & $5.1 \%$ & 967 & $5.9 \%$ \\
\hline & non-responder & 569 & $5.4 \%$ & 374 & $2.3 \%$ \\
\hline \multirow[t]{5}{*}{ Rank } & Officer & 1603 & $15.4 \%$ & 3418 & $20.8 \%$ \\
\hline & Enlisted & 5829 & $55.8 \%$ & 8941 & $54.5 \%$ \\
\hline & Soldier & 2194 & $21.0 \%$ & 3313 & $20.2 \%$ \\
\hline & Cadet & 572 & $5.5 \%$ & 374 & $2.3 \%$ \\
\hline & non-responder & 244 & $2.3 \%$ & 349 & $2.1 \%$ \\
\hline
\end{tabular}

The body location of the injury included $31.9 \%$ in the upper extremity, $23.1 \%$ in the trunk, and $45.0 \%$ in the lower extremities. The most common body location of injury was the knee followed by the hand/finger and the ankle. On the other hand, musculoskeletal disorders were reported $17.5 \%$ in the upper extremity, $40 \%$ in the trunk, and $42.5 \%$ in the lower extremity. The most common body location of the disorder was the lumbar spine, followed by the knee and the cervical spine (Table 2).

Exercise was the most common cause of injury (48. $8 \%)$, followed by traffic accident (14.8\%) and military training (13.3\%). Exercise was the most popular cause of injury in younger generations, and the occurrence rate was more than $50 \%$ in the second and the third decades. The rate of traffic accident rose as the generation rose, but those of military training were not difference among the generations. During activities of daily living (ADL) and repairing work, traumatic injury increased with age (Table 3).

Injury classification revealed that contusion (29.7\%) was the most common, followed by sprain (26.8\%) and fracture (11.5\%). These injuries showed similar occurrence across age decades, and, in particular, the ratio of fracture was around $12 \%$ of injuries in every decade of age. The prevalence of tendon and ligament injuries was higher in younger generations (Table 4). A comparison of occurrence by diagnoses in the nontraumatic disorders showed a higher rate with lumbar (27.7\%), tendon (23.2\%), and joint disorders (16.1\%). Lumbar disorder was the most common in each generation, with the highest rate in the fourth decade. Joint disorder or periarthritis was the most common in the sixth decade, and the incidence was increasing with age. Ligament disorder, bone bruise or the fatigue fracture was the most common disorder in the 
Table 2 Comparison of body location between traumatic injuries and non-traumatic disorders

\begin{tabular}{|c|c|c|c|c|c|c|c|c|c|c|}
\hline & & \multicolumn{3}{|c|}{ Traumatic injuries } & \multicolumn{3}{|c|}{ Non-traumatic disorders } & \multicolumn{3}{|l|}{ Total } \\
\hline & & $n$ & $\%$ & $\%$ & $n$ & $\%$ & $\%$ & $\bar{n}$ & $\%$ & $\%$ \\
\hline \multirow[t]{6}{*}{ Upper extremities } & Shoulder & 930 & 8.9 & 31.9 & 1194 & 7.3 & 17.5 & 2124 & 7.9 & 23.1 \\
\hline & Upper arm & 95 & 0.9 & & 488 & 3.0 & & 583 & 2.2 & \\
\hline & Elbow & 353 & 3.4 & & 325 & 2.0 & & 678 & 2.5 & \\
\hline & Forearm & 96 & 0.9 & & 54 & 0.3 & & 150 & 0.6 & \\
\hline & Wrist & 385 & 3.7 & & 330 & 2.0 & & 715 & 2.7 & \\
\hline & Hand/Finger & 1473 & 14.1 & & 475 & 2.9 & & 1948 & 7.3 & \\
\hline \multirow[t]{4}{*}{ Trunk } & Cervical spine & 583 & 5.6 & 23.1 & 1506 & 9.2 & 40.0 & 2089 & 7.8 & 33.5 \\
\hline & Thoracic spine & 17 & 0.2 & & 12 & 0.1 & & 29 & 0.1 & \\
\hline & Thorax & 933 & 8.9 & & 405 & 2.5 & & 1338 & 5.0 & \\
\hline & Lumbar spine & 881 & 8.4 & & 4642 & 28.3 & & 5523 & 20.6 & \\
\hline \multirow[t]{6}{*}{ Lower extremities } & Hip & 77 & 0.7 & 45.0 & 342 & 2.1 & 42.5 & 419 & 1.6 & 43.4 \\
\hline & Femur & 361 & 3.5 & & 587 & 3.6 & & 948 & 3.5 & \\
\hline & Knee & 1620 & 15.5 & & 3263 & 19.9 & & 4883 & 18.2 & \\
\hline & Lower leg & 464 & 4.4 & & 1189 & 7.3 & & 1653 & 6.2 & \\
\hline & Ankle & 1335 & 12.8 & & 484 & 3.0 & & 1819 & 6.8 & \\
\hline & Foot/Toe & 839 & 8.0 & & 1099 & 6.7 & & 1938 & 7.2 & \\
\hline Total & & 10,442 & 100 & 100 & 16,395 & 100 & & 26,837 & 100 & 100 \\
\hline
\end{tabular}

second decade, and the incidence was decreasing with age (Table 5).

Traffic accident was the most common cause of fracture (19.2\%). Military training was the most common cause of ligament injury (18.3\%). Maintenance work was the most common cause of contusion (11.7\%). Contusion, sprain, and fracture occurred the second most from traffic accident, while ligament, tendon, and joint injuries and dislocation occurred during military training.

The number of patients in the fracture group was 1206 (male, 1124; female, 78; non-responders, 4), while that in the non-fracture group was 9236 (male, 8612; female, 582; non-responders, 42). The weight group distributed as shown in Table 6 . The body weight and the body mass index in the fracture group were significantly lower than that in the non-fracture group $(p<0.001)$. In regards to gender and the body weight class, males showed a significant difference between the groups $(p<0$. 001), but females did not. Uni-variable analysis revealed no difference in the smoking or alcohol habit between the two groups. Multivariable analysis revealed that BMI was the only significant risk factor $(p<0.001)$. A lower BMI correlated more strongly with fracture.

\section{Discussion}

An advantage of this study is that the sample was a young homogeneous population. Because military personnel are homogeneous and closed society, they are an appropriate population for epidemiological study, and many studies relating to musculoskeletal injury or

Table 3 Cause of traumatic injury by decades of age

\begin{tabular}{|c|c|c|c|c|c|c|c|c|c|c|c|c|}
\hline \multirow[t]{2}{*}{ Age (y) } & \multicolumn{2}{|c|}{$15-19$} & \multicolumn{2}{|c|}{$20-29$} & \multicolumn{2}{|l|}{$30-39$} & \multicolumn{2}{|c|}{$40-49$} & \multicolumn{2}{|c|}{$50-60$} & \multicolumn{2}{|l|}{ Total } \\
\hline & $n$ & $\%$ & $n$ & $\%$ & $n$ & $\%$ & $n$ & $\%$ & $n$ & $\%$ & $n$ & $\%$ \\
\hline Exercise & 357 & 62.3 & 2111 & 57.9 & 1358 & 47.4 & 938 & 38.3 & 323 & 35.6 & 5087 & 48.8 \\
\hline Traffic accident & 60 & 10.5 & 450 & 12.3 & 404 & 14.1 & 449 & 18.3 & 184 & 20.3 & 1547 & 14.8 \\
\hline Military training & 72 & 12.6 & 535 & 14.7 & 388 & 13.6 & 295 & 12.0 & 94 & 10.4 & 1384 & 13.3 \\
\hline ADL & 39 & 6.8 & 229 & 6.3 & 304 & 10.6 & 334 & 13.6 & 145 & 16.2 & 1051 & 10.1 \\
\hline Repairing work & 29 & 5.1 & 245 & 6.7 & 269 & 9.4 & 273 & 11.1 & 101 & 11.2 & 917 & 8.8 \\
\hline Other & 7 & 1.2 & 24 & 0.7 & 52 & 1.8 & 38 & 1.5 & 16 & 1.7 & 137 & 1.1 \\
\hline Non-responder & 9 & 1.6 & 52 & 1.4 & 89 & 3.1 & 125 & 5.1 & 44 & 4.9 & 319 & 3.1 \\
\hline
\end{tabular}


Table 4 Traumatic injury classification by decades of age

\begin{tabular}{|c|c|c|c|c|c|c|c|c|c|c|c|c|}
\hline \multirow[t]{2}{*}{ Age (y) } & \multicolumn{2}{|c|}{ 15-19 } & \multicolumn{2}{|c|}{$20-29$} & \multicolumn{2}{|c|}{ 30-39 } & \multicolumn{2}{|c|}{ 40-49 } & \multicolumn{2}{|c|}{$50-60$} & \multicolumn{2}{|l|}{ Total } \\
\hline & $n$ & $\%$ & $n$ & $\%$ & $n$ & $\%$ & $n$ & $\%$ & $n$ & $\%$ & $n$ & $\%$ \\
\hline Contusion & 135 & 23.6 & 1054 & 28.9 & 844 & 29.5 & 695 & 28.3 & 270 & 29.8 & 2998 & 28.7 \\
\hline Sprain & 160 & 27.9 & 964 & 26.4 & 778 & 27.2 & 669 & 27.3 & 230 & 25.4 & 2801 & 26.8 \\
\hline Fracture & 67 & 11.7 & 413 & 11.3 & 316 & 11.0 & 301 & 12.3 & 109 & 12.0 & 1206 & 11.5 \\
\hline Ligament injury & 94 & 16.4 & 497 & 13.6 & 315 & 11.0 & 212 & 8.6 & 47 & 5.2 & 1165 & 11.2 \\
\hline Tendon injury & 51 & 8.9 & 310 & 8.5 & 299 & 10.4 & 266 & 10.8 & 114 & 12.6 & 1040 & 10.0 \\
\hline Joint injury & 35 & 6.1 & 216 & 5.9 & 189 & 6.6 & 203 & 8.3 & 95 & 10.5 & 738 & 7.1 \\
\hline Dislocation & 25 & 4.4 & 125 & 3.4 & 69 & 2.4 & 44 & 1.8 & 10 & 1.1 & 273 & 2.6 \\
\hline Periarthritis & 2 & 0.3 & 28 & 0.8 & 31 & 1.1 & 35 & 1.4 & 23 & 2.5 & 119 & 1.1 \\
\hline Nerve injury & 1 & 0.2 & 12 & 0.3 & 12 & 0.4 & 14 & 0.6 & 5 & 0.6 & 44 & 0.4 \\
\hline Incision wound & 2 & 0.3 & 20 & 0.5 & 5 & 0.2 & 8 & 0.3 & 2 & 0.2 & 37 & 0.4 \\
\hline Other & 1 & 0.2 & 7 & 0.2 & 6 & 0.2 & 5 & 0.2 & 2 & 0.2 & 21 & 0.2 \\
\hline
\end{tabular}

disorder in this population have been published (Hauret et al., 2010). Since 1988, automated outpatient surveillance data has been available for the United States Military services, and that data is useful for determining the magnitude and causes of injury, identifying possible prevention targets, and monitoring trends among military personnel (Jones et al., 2010). In contrast, Japan Self-Defense Forces have not constructed such a surveillance system, and the incidence or outline of musculoskeletal problems is not clear. This study investigated musculoskeletal injuries or disorders in the large population of Japan Self-Defense Forces. This was the first epidemiological surveillance of young, athletic population of Japanese military members, This study revealed that body height and weight was very homogeneous, and all of the population belong to the Japan Self-Defense Forces. They were selected by entrance examination, and they undergo physical tests every year. The population could be representative of young and active adult individuals in Japan. However, these injuries are important in terms of loss of time in their duties or training.

The United States military reported that $74 \%$ of combat wounds occurred in the extremities during Operation Iraqi Freedom and Operation Enduring Freedom (Owens et al., 2007; Goodman et al., 2012; Belmont Jr et al., 2011). The leading causes of medical evacuation were musculoskeletal and connective tissue disorders (Cohen et al., 2010). United States Military surveillance showed that the most common location was the wrist, hand, and finger (13\%), followed by the ankle (12\%) (Jones et al., 2010). Non-combat injuries were reported by the United States Army Brigade Combat Team during Operation Iraqi Freedom, and the most common region of injury was the hand (17.5\%), followed by the

Table 5 Non-traumatic musculoskeletal disorder classification by decades of age

\begin{tabular}{|c|c|c|c|c|c|c|c|c|c|c|c|c|}
\hline \multirow[t]{2}{*}{ Age (y) } & \multicolumn{2}{|c|}{$15-19$} & \multicolumn{2}{|c|}{$20-29$} & \multicolumn{2}{|l|}{$30-39$} & \multicolumn{2}{|l|}{$40-49$} & \multicolumn{2}{|c|}{$50-60$} & \multicolumn{2}{|l|}{ Total } \\
\hline & $n$ & $\%$ & $n$ & $\%$ & $n$ & $\%$ & $n$ & $\%$ & $n$ & $\%$ & $n$ & $\%$ \\
\hline Lumbar disorder & 256 & 23.4 & 1115 & 26.8 & 1225 & 32.3 & 1370 & 27.7 & 582 & 24.2 & 4548 & 27.7 \\
\hline Tendon disorder & 276 & 25.3 & 1098 & 26.4 & 824 & 21.7 & 1079 & 21.8 & 529 & 22.0 & 3806 & 23.2 \\
\hline Joint disorder & 140 & 12.8 & 566 & 13.6 & 511 & 13.5 & 915 & 18.5 & 501 & 20.8 & 2633 & 16.1 \\
\hline Cervical disorder & 10 & 0.9 & 157 & 3.8 & 404 & 10.6 & 614 & 12.4 & 261 & 10.9 & 1446 & 8.8 \\
\hline Periarthritis & 42 & 3.8 & 176 & 4.2 & 189 & 5.0 & 400 & 8.1 & 252 & 10.5 & 1059 & 6.5 \\
\hline Ligament disorder & 129 & 11.8 & 442 & 10.6 & 191 & 5.0 & 180 & 3.6 & 69 & 2.9 & 1011 & 6.2 \\
\hline Bone bruise & 121 & 11.1 & 216 & 5.2 & 104 & 2.7 & 70 & 1.4 & 40 & 1.7 & 551 & 3.4 \\
\hline Nerve disorder & 23 & 2.1 & 102 & 2.5 & 121 & 3.2 & 127 & 2.6 & 67 & 2.8 & 440 & 2.7 \\
\hline Fatigue fracture & 54 & 4.9 & 93 & 2.2 & 40 & 1.1 & 42 & 0.8 & 11 & 0.5 & 240 & 1.5 \\
\hline Tumor & 15 & 1.4 & 49 & 1.2 & 72 & 1.9 & 58 & 1.2 & 41 & 1.7 & 235 & 1.4 \\
\hline Other & 27 & 2.5 & 140 & 3.4 & 108 & 2.9 & 97 & 2.0 & 54 & 2.2 & 426 & 2.6 \\
\hline Total & 1093 & 100.0 & 4154 & 100.0 & 3789 & 99.9 & 4952 & 100.0 & 2353 & 100.1 & 16,395 & 100.0 \\
\hline
\end{tabular}


Table 6 Odds ratios for fracture according to sex and body weight class

\begin{tabular}{|c|c|c|c|c|c|c|}
\hline & & $p$ value & $\begin{array}{l}\text { Underweight } \\
(n=70)\end{array}$ & $\begin{array}{l}\text { Normal weight } \\
(n=6720)\end{array}$ & $\begin{array}{l}\text { Overweight } \\
(n=2512)\end{array}$ & $\begin{array}{l}\text { Obese } \\
(n=434)\end{array}$ \\
\hline All injuries & $(n=10,442)$ & $<0.001$ & $2.187(1.390-3.329)$ & 1.0 (reference) & $0.917(0.794-1.057)$ & $0.584(0.397-0.829)$ \\
\hline Male only & $(n=9736)$ & $<0.001$ & $2.977(1.725-4.947)$ & 1.0 (reference) & $0.919(0.793-1.061)$ & $0.592(0.403-0.842)$ \\
\hline Female only & $(n=660)$ & 0.7857 & $1.268(0.504-2.774)$ & 1.0 (reference) & $1.087(0.363-2.640)$ & N/A \\
\hline
\end{tabular}

knee, lumbar spine, and ankle (13.5\% each) (Belmont Jr. et al., 2010). Our study revealed that the knee was the most common injury location, followed by the hand/finger, and ankle. These slight variances can be explained by the character of the study population, but the common location of traumatic injury for young adults is the knee, hand/finger, and ankle. Approximately half of the injuries $(48.8 \%)$ were sprain in the United States Military surveillance, followed by contusion (16.3\%) and fracture (9.8\%) (Belmont Jr et al., 2011). The reasons that sprain is so common in the United States Military are unclear, but the occurrence rate of fracture is around 10\% in both the United States Military and Japan Self-Defense Forces.

Although musculoskeletal traumatic injury is a common problem, most studies have been conducted in rural villages in Japan, the target population of their studies was elderly people, and the degenerative disorders have been clarified in those studies (Muraki et al., 2010; Yoshimura et al., 2009; Yoshimura et al., 2011; Tsunoda et al., 2013). Few studies have examined the type of musculoskeletal injuries, body location, magnitude, and causes of the musculoskeletal problems for the younger population. The Japan Amateur Sports Association (JASA) also reported the sports related injury, and the most common sports related injury was fracture $(27$. 9\%), followed by sprain (24.5\%) and contusion (24.5\%) (Fukubayashi et al., 2010; Fukubayashi et al., 2012; Fukubayashi et al., 2013). However, our results demonstrated that the most common traumatic injury was contusion (28.7\%), followed by sprain (26.8\%) and fracture $(11.5 \%)$. Since that population of JASA was composed of applicants to the sports insurance system, non-applicants were excluded in the report, and minor injuries were not included. Contusion or sprain was very common, but minor, and the occurrence of such minor injury has not been well documented.

Character of non-traumatic musculoskeletal disorders in young population has not been well-known. Nakamura reported a cross sectional study of chronic musculoskeletal pain in Japan, but their population was not so young. They focused on chronic pain, and chronic pain occurred most commonly in the lower back (Nakamura et al., 2011). Our study showed that the non-traumatic disorder was also localized mainly to the lumbar spine, followed by the knee, and the cervical spine. However, in younger generation the incidence of ligament disorder, bone bruise or fatigue fracture was relatively higher than other generation. Although acute trauma may be a factor in some cases, many musculoskeletal disorders result from the cumulative effects of smaller amplitude forces during exercise of military training. These forces occur with overtraining, overexertion, repetitive movement and activities, and forceful actions, and further study is required to identified risk factor of the disorders, and to develop preventive measures (Sasao et al., 2012),.

Our final goal of this study was to prevent musculoskeletal injuries or disorders in Japan Self Defense Forces. van Mechelen revealed the measures to prevent sports injuries form part of what is called the 'sequence of prevention' (van Mechelen et al., 1992). Firstly the extent of the sports injury problem must be identified and described. Secondly the factors and mechanisms have to be identified. The third step is to introduce measures that are likely to reduce the future risk and/or severity of sports injuries. Finally the effect of the measures must be evaluated by repeating the first step. This study was the first step to develop preventive measures, and we could make clear many epidemiological facts in our population; $45 \%$ of injury occurred in the lower extremities, especially in the knee, exercise was the most common cause of injury, contusion was the common injury classification, and lumbar spine was the most common body location of the disorders. We have to continue our study to identify the mechanism and risk factors, and introduce a preventive measure, and assess its effectiveness by repeating the first step.

Fracture occurred in $11-12 \%$ of the injured population in the present study, and the patients with fracture require a lot of time and expense to resume their duties (Matsuhashi et al., 2014). The increase in the prevalence of obesity may increase the fracture burden among young women and children, but not young men (Jordan et al., 2013; Lazcano-Ponce et al., 2009; Kessler et al., 2013; Rana et al., 2009). While active lifestyles have health benefits, our results highlight the importance of injury prevention practices in conjunction with physical activity recommendations, particularly among women. Our results indicate that the risk factor of fracture was low body weight among the male population. Among 
the high-activity population, a lower body weight may indicate lower bone density, and increased incidence of fracture during strenuous exertion of the upper and lower extremities.

A disadvantage of the study is that the population was composed of patients who visited the Self-Defense Forces Hospitals. Healthy people without musculoskeletal problems were not included in this study. The diagnoses were conducted at the initial visit, and may have changed during the treatment periods. All patients belong to Japan Self-Defense Forces, and the number of female patients was quite low (6.7\%). This study did not investigate the magnitude of injuries or disorders.

\section{Conclusions}

This study investigated musculoskeletal injuries or disorders in the large population of the Japan Self-Defense Forces. This was the first epidemiological surveillance of young, athletic population of Japanese military members, and character of musculoskeletal problems were obtained: $45 \%$ of injury occurred in the lower extremities, and the most common body location of injury was the knee, exercise was the most common cause of injury, contusion was the most common injury classification, the most common body location of the musculoskeletal disorder was the lumbar spine, and low BMI was only the risk factor for fracture in the traumatic injuries.

\section{Abbreviations}

ADL: Activities of daily living; BMl: Body mass index

\section{Acknowledgements}

We wish to express our thanks to Drs. Yukio Ueda, Yasuhiro Matsueda, Atsuhiro Mitsumaru, Akira Kitada, Kenichi Sugimoto, Hiroto Ichiki, Hiroshi Shimizu, Masahisa Kawaguchi, Kensuke Mio, Hideaki Imabayashi, Kazuki Ohashi, Satoko Naito, Masamitsu Tanaka, Toyokazu Tsuchihara, Masashi Matsunaga, Toshitaka Okabayashi, Daiki Kaneko, Ryuji Koga, Yuichiro Shiromoto, Koichiro Tanaka, Yoshifumi Tsuda, Yoshikazu Nakayama, Tsubasa Sakai, Yoshitaka Tanaka, Shigeyuki Yoshida, Tomoki Kawano, Akiyo Ohtsuka, Masahiro Yamashiro, Koji Yamamoto, Junya Yokobe, Shigekazu Watanabe, Masatoshi Kuwakubo, Makoto Takigawa, Keitaro Matsukawa, Masahiko Mihara, Shinichiro Akinaga, Yohei Iguchi, Tsukuru Nakaya, Takashi Fujiki, Jun Kasahara, Daiki Takai, Atsuko Tachibana, Masato Tatsumi, Yuya Itoh, Takashi Kato, Kohei Tamura, Masamoto Hirano, Shintaro Ohno, Eiko Taguchi, Yusuke Matsuhashi, Masahiro Inoue, Yasufumi Hirahara, Yoshihide Yanai, Hajime Rikitake, Takahiro Ishizaka for their contribution of collecting data in JapanSelf-Defense Forces Hospitals.

\section{Funding}

This study was funded by a Science Project Research from the Japanese Orthopaedic Association (2009-2011) in analysis of data.

\section{Availability of data and materials}

The datasets during and/or analyzed during the current study available from the corresponding author on reasonable request.

\section{Authors' contributions}

$\mathrm{HS}, \mathrm{ON}, \mathrm{TI}, \mathrm{AS}$ and ST contributed data collection, analysis, and interpretation. $Y Y, Y Y$ and $H A$ contributed critical review of manuscript and data interpretation. YS and KN provided the study concept and project supervision, and contributed to data analysis, interpretation, and manuscript writing. All authors read and approved the final manuscript.

\section{Ethics approval and consent to participate}

This study was approved by National Defense Medical College Medical Ethics Committee (IRB No. 895), and we obtained consent to participate by all participants.

\section{Consent for publication}

Not applicable

\section{Competing interests}

The authors declare that they have no competing interests.

\section{Author details}

${ }^{1}$ Department of Orthopaedic Surgery, National Defense Medical College, 3-2 Namiki, Tokorozawa, Saitama 359-8513, Japan. ${ }^{2}$ Department of Orthopaedic Surgery, Japan Self-Defense Forces Central Hospital, Setagaya, Tokyo, Japan. ${ }^{3}$ Department of Orthopaedic Surgery, Japan Self-Defense Forces Sapporo Hospital, Sapporo, Hokkaido, Japan. ${ }^{4}$ Department of Orthopaedic Surgery, Japan Self-Defense Forces Hospital Kure, Kure, Hiroshima, Japan.

${ }^{5}$ Department of Orthopaedic Surgery, Japan Self-Defense Forces Hospital Yokosuka, Yokosuka, Kanagawa, Japan. ${ }^{6}$ Department of Public Health and Preventive Medicine, National Defense Medical College, Tokorozawa, Saitama, Japan.

Received: 13 December 2017 Accepted: 21 March 2018

Published online: 01 May 2018

\section{References}

Belmont PJ Jr, Thomas D, Goodman GP, Schoenfeld AJ, Zacchilli M, Burks R, Owens BD. Combat musculoskeletal wounds in a US Army Brigade Combat Team during operation Iraqi Freedom. J Trauma. 2011;71(1):E1-7.

Belmont PJ Jr, Goodman GP, Waterman B, DeZee K, Owens BD. Disease and nonbattle injuries sustained by a U.S. Army brigade combat team during operation Iraqi freedom. Mil Med. 2010;175(7):469-76.

Cohen SP, Brown C, Kurihara C, Plunkett A, Nguyen C, Strassels SA. Diagnoses and factors associated with medical evacuation and return to duty for service members participating in operation Iraqi freedom or operation enduring freedom: a prospective cohort study. Lancet. 2010;375(9711):301-9.

Frilander H, Miranda H, Mutanen P, Martelin T, Pihlajamäki H, Viikari-Juntura E. Trends in musculoskeletal disorders and related health care utilization among conscripts in Finland, 1967-2006. Mil Med. 2012;177(9):1069-74.

Fukubayashi T, Ikeda H, Ogasawara K, Okuwaki T, Kato H, Shimizu Y, Tsuda K, Nakabori C, Fujitani H, Furuya M, Matsuda N, Miki H, Aono H. In: Fukubayashi T, editor. Construction of sports injury surveillance system in Japan. The first report. Report of medical science research. Tokyo: Japan Amateur Sports Association; 2010. p. 1-68. (In Japanese).

Fukubayashi T, Ikeda H, Okuwaki T, Shimizu Y, Tsuda K, Nakata K, Nakabori C, Fujitani H, Furuya M, Matsuda N, Miki H, Miyazaki M, Aono H. In: Fukubayashi T, editor. Construction of sports injury surveillance system in Japan. The second report. Report of medical science research. Tokyo: Japan Amateur Sports Association; 2012. p. 1-67. (In Japanese).

Fukubayashi T, Ikeda H, Okuwaki T, Shimizu Y, Tsuda K, Nakata K, Nakabori C, Fujitani H, Furuya M, Matsuda N, Miki H, Miyazaki M, Aono H. In: Fukubayashi T, editor. Construction of sports injury surveillance system in Japan. The third report. Report of medical science research 2012. Tokyo: Japan Amateur Sports Association; 2013. p. 1-97. (In Japanese).

Goodman GP, Schoenfeld AJ, Owens BD, Dutton JR, Burks R, Belmont PJ. Nonemergent orthopaedic injuries sustained by soldiers in Operation Iraqi Freedom. J Bone Joint Surg Am. 2012;94(8):728-35.

Haskell WL, Lee IM, Pate RR, Powell KE, Blair SN, Franklin BA, Macera CA, Heath GW, Thompson PD, Bauman A. American College of Sports Medicine; American Heart Association. Physical activity and public health: updated recommendation for adults from the American College of Sports Medicine and the American Heart Association. Circulation. 2007;116(9):1081-93.

Hauret KG, Jones BH, Bullock SH, Canham-Chervak M, Canada S. Musculoskeletal injuries. Description of an under-recognized injury problem among military personnel. Am J Prev Med. 2010;38(1 Suppl):S61-70.

Japan Health, Labor and Welfare Ministry. Causes of long-term nursing care need in Japan (Internet). 2017. http://www.mhlw.go.jp/toukei/saikin/hw/k-tyosa/ktyosa16/dl/05.pdf. Accessed 1 Nov 2017. 
Jones BH, Canham-Chervak M, Canada S, Mitchener TA, Moore S. Medical Surveillance of Injuries in the U.S. Military: Descriptive Epidemiology and Recommendations for Improvement. Am J Prev Med. 2010;38(1 Suppl):S42-60. Jones BH, Cowan DN, Tomlinson JP, Robinson JR, Polly DW, Frykman PN. Epidemiology of injuries associated with physical training among young men in the army. Med Sci Sports Exerc. 1993;25(2):197-203.

Jordan S, Lim L, Berecki-Gisolf J, Bain C, Seubsman SA, Sleigh A, Banks E, Thai Cohort Team. Body mass index, physical activity, and fracture among young adults: longitudinal results from the Thai cohort study. J Epidemiol. 2013; 23(6):435-42.

Kessler J, Koebnick C, Smith N, Adams A. Childhood obesity is associated with increased risk of most lower extremity fractures. Clin Orthop Relat Res. 2013; 471(4):1199-207.

Lazcano-Ponce E, Tamayo J, Díaz R, Burguete Al, Salmerón J. Correlation trends for bone mineral density in Mexican women: evidence of familiar predisposition. Salud Publica Mex. 2009;51(Suppl 1):s93-9.

Matsuhashi Y, Amako M, Yato Y, Nemoto K, Sasao H, Tsukazaki S. Epidemiological study of fracture in adolescent members of the self-defense forces. Kossetsu (Fracture). 2014;36(2):426-9. (in Japanese)

Muraki S, Akune T, Oka H, En-yo Y, Yoshida M, Saika A, Suzuki T, Yoshida H. Association of radiographic and symptomatic knee osteoarthritis with healthrelated quality of life in a population-based cohort study in Japan: the ROAD study. Osteoarthr Cartil. 2010;18(9):1227-34.

Nakamura M, Nishiwaki Y, Ushida T, Toyama Y. Prevalence and characteristics of chronic musculoskeletal pain in Japan. J Orthop Sci. 2011;16(4):424-32.

Owens BD, Kragh JF Jr, Macaitis J, Svoboda SJ, Wenke JC. Characterization of extremity wounds in Operation Iraqi Freedom and Operation Enduring Freedom. J Orthop Trauma. 2007;21(4):254-7.

Rana AR, Michalsky MP, Teich S, Groner Jl, Caniano DA, Schuster DP. Childhood obesity: a risk factor for injuries observed at a level-1 trauma center. J Pediatr Surg. 2009:44(8):1601-5.

Sasao H, Yato Y, Amako M, Ueda Y, Mitsumaru A, Ichiki H, Tajima T, Tsukazaki S, Nemoto O, Sakurai Y. Epidemiologic study of musculoskeletal injuries and disorders: lumbar injuries and disorders in adolescents. J Natl Def Med Coll. 2012;37(3):203-9. (in Japanese).

Taanila H, Suni J, Pihlajamäki H, Mattila VM, Ohrankämmen O, Vuorinen P, Parkkari J. Musculoskeletal disorders in physically active conscripts: a one-year followup study in the Finnish Defence Forces. BMC Musculoskelet Disord. 2009;10: 89. https://doi.org/10.1186/1471-2474-10-89.

The World Health Organization BMI classification. The International Classification of adult underweight, overweight and obesity according to BMI. 1994. http:// apps.who.int/bmi/index.jsp?introPage=intro_3.html Accessed 1 Feb 2018.

Tsunoda D, lizuka Y, lizuka H, Nishinome M, Kobayashi R, Ara T, Yamamoto A, Takagishi K. Associations between neck and shoulder pain (called katakori in Japanese) and sagittal spinal alignment parameters among the general population. J Orthop Sci. 2013;18(2):216-9.

van Mechelen W, Hlobil H, Kemper HC. Incidence, severity, aetiology and prevention of sports injuries. A review of concepts. Sports Med. 1992;14(2):82-99.

Yoshimura N, Muraki S, Oka H, Kawaguchi H, Nakamura K, Akune T. Association of knee osteoarthritis with the accumulation of metabolic risk factors such as overweight, hypertension, dyslipidemia, and impaired glucose tolerance in Japanese men and women: the ROAD study. J Rheumatol. 2011;38(5):921-30

Yoshimura N, Muraki S, Oka H, Mabuchi A, En-Yo Y, Yoshida M, Saika A, Yoshida H, Suzuki T, Yamamoto S, Ishibashi H, Kawaguchi H, Nakamura K, Akune T. Prevalence of knee osteoarthritis, lumbar spondylosis, and osteoporosis in Japanese men and women: the research on osteoarthritis/osteoporosis against disability study. J Bone Miner Metab. 2009;27(5):620-8.

Submit your manuscript to a SpringerOpen ${ }^{\circ}$ journal and benefit from:

- Convenient online submission

- Rigorous peer review

- Open access: articles freely available online

- High visibility within the field

- Retaining the copyright to your article

Submit your next manuscript at springeropen.com 